\title{
Declining life expectancy in the United States
}

\author{
Gilbert Berdine MD
}

The Centers for Disease Control and Prevention (CDC) released the life expectancy figures for 2017 on November 28, 2018. ${ }^{1}$ These figures demonstrate a further decline in U.S. life expectancy from 78.7 years in 2016 to 78.6 years in 2017. This represents the third consecutive year that the CDC reported a decline in life expectancy. Subsequent revisions have changed one decline to unchanged. The last time in U.S. history that life expectancy failed to improve year to year over three consecutive years was 100 years ago from 1916-1918 due to the Spanish Flu pandemic. The cause of our current decline in life expectancy is not infectious disease, but rather a rising rate of suicides in general and opioid overdoses in particular.

Figure 1 illustrates U.S. life expectancy from 19672017. Data were obtained from the CDC. ${ }^{1,2}$ Life expectancy peaked in 2014 at 78.9 years for the total U.S. population. The last year that U.S. life expectancy was less than the 2017 value of 78.6 years was in 2009 when life expectancy was 78.5 years. The U.S. has experienced a lost decade for life expectancy. Figure 1 demonstrates three broad periods since 1967. From 1967 to 1979 life expectancy increased from 70.5 years to 73.9 years or 0.28 years per year. From 1979 to 2010 life expectancy increased from 73.9 years to 78.7 years or 0.15 years per year. From 2010 to 2017 life expectancy has decreased from 78.7 years to 78.6 years and the declining trend that is most apparent since 2014 does not show signs of reversing.

Figure 2 illustrates U.S. mortality rates by age groups from the years 2000-2017. Data were obtained from the CDC Wonder database. ${ }^{3}$ Figure 2 and Table 1 show that since 2010 the mortality rate is rising for young people (age 15-44), is flat for middle age people (age 45-64),

Corresponding author: Gilbert Berdine

Contact Information: Gilbert.berdine@ttuhsc.edu

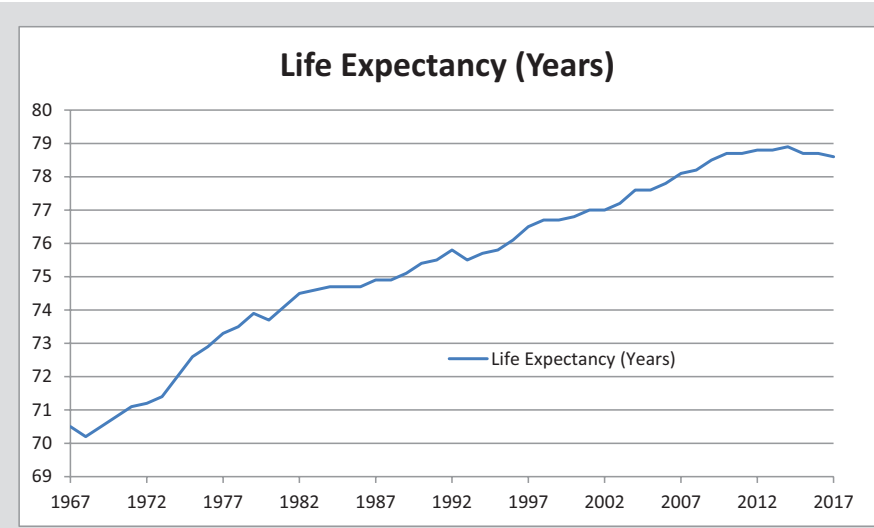

Figure 1. U.S. Life Expectancy in Years. ${ }^{1,2}$

and is falling slowly for senior people (age 65 and older). The rising mortality rates for young people are attributed to suicides in general and opioid overdoses in particular. These are deaths of despair. Unlike the Spanish Flu pandemic from 1916-1918, suicide is not caused by an infectious agent that can be treated with antibiotics or vaccines. It is unclear what is causing despair in young people during a period of time when we are told that the economy is expanding.

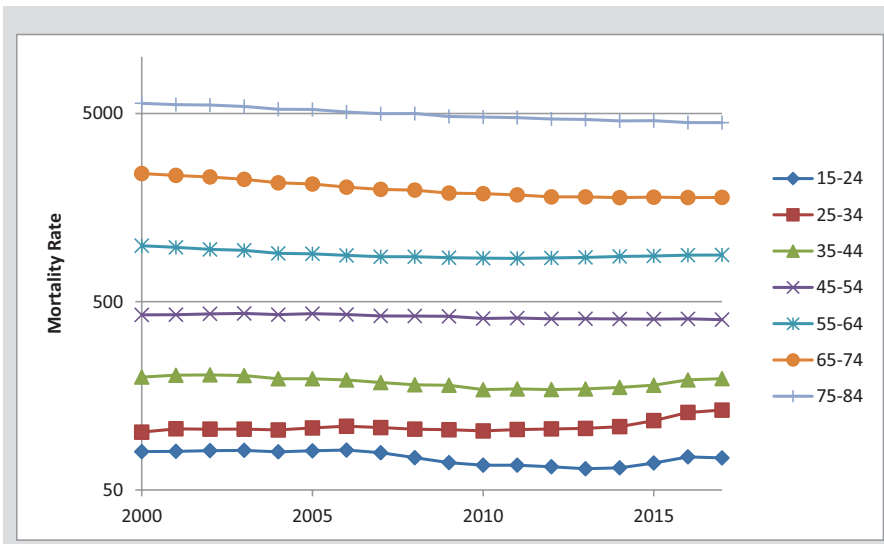

Figure 2. Deaths per 100,000 population. 
Table 1. Comparison in mortality rates per 100,000 by age group between 2010 and 2017

\begin{tabular}{|l|c|c|c|}
\hline Age Group & $\mathbf{2 0 1 0}$ & $\mathbf{2 0 1 7}$ & \% Change \\
\hline $\mathbf{1 5}-\mathbf{2 4}$ & 67.7 & 74 & +9.31 \\
\hline $\mathbf{2 5}-\mathbf{3 4}$ & 102.9 & 132.8 & +29.06 \\
\hline $\mathbf{3 5}-\mathbf{4 4}$ & 170.5 & 195.2 & +14.49 \\
\hline $\mathbf{4 5}-\mathbf{5 4}$ & 407.1 & 401.5 & -1.38 \\
\hline $\mathbf{5 5}-\mathbf{6 4}$ & 851.9 & 885.8 & +3.98 \\
\hline $\mathbf{6 5}-\mathbf{7 4}$ & 1875.1 & 1790.9 & -4.49 \\
\hline $\mathbf{7 5}-\mathbf{8 4}$ & 4790.2 & 4472.6 & -6.63 \\
\hline
\end{tabular}

Figure 3 illustrates the labor force participation rate in January of each year from 1967-2017. The data were obtained from the Bureau of Labor Statistics (BLS). ${ }^{4}$ The labor force participation rate is the number of people available for work as a fraction of the total population. The unemployment rate, which is currently low, excludes people who have given up searching for a job. The peak labor force participation rate occurred in the year 2000 .

It is plausible that times of increasing labor participation are associated with optimism and times of

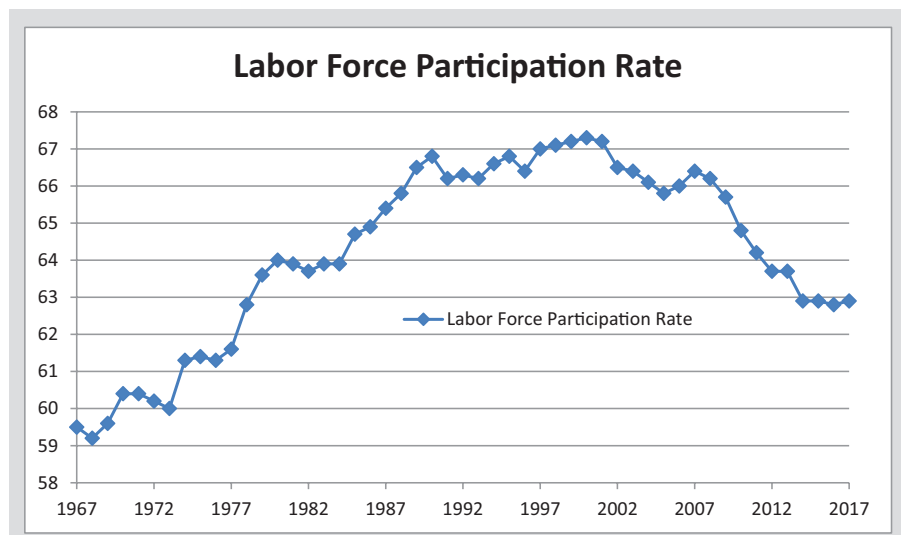

Figure 3. Labor Force Participation Rate. decreasing labor participation are associated with pessimism. Employers add workers when they anticipate a growth in sales and a need to increase production. Employers fire workers when they anticipate a decline in sales and a need to decrease production. Recent announcements by General Motors to close production facilities and decrease employment are an example. ${ }^{5}$ Employers hire workers only when employers expect to increase profit by adding workers. Mandated employment expenses, such as health care and payroll taxes (Social Security and Medicare), make workers less attractive to employers. Faced with an increase in mandated employment expenses, employers will consider a relocation of production to somewhere with lower employment expenses. Society needs to consider that policies which decrease labor force participation may be partially responsible for the increase in suicides that are causing life expectancy in the U.S. to decline.

Keywords: life expectancy, narcotics, suicide, labor participation, United States

Submitted: $12 / 6 / 2018$

\section{REFERENCES}

1. Murphy SL, Xu JQ, Kochanek KD, et al. Mortality in the United States, 2017. NCHS Data Brief 2018;328.

2. Arias E, Xu JQ. United States life tables, 2015. National Vital Statistics Reports. 2018;67(7).

3. Underlying cause of death, 1999-2017 request. Centers for Disease Control. https://wonder.cdc.gov/ucd-icd10.html. Accessed $12 / 8 / 2018$.

4. Labor force statistics. Bureau of Labor Statistics. https://www. bls.gov/webapps/legacy/cpsatab16.htm. Accessed 12/8/2018.

5. Capparella, J. GM closing plants, ending production of multiple models; President Trump threatens retribution. Car and Driver. https://www.caranddriver.com/news/a25306076/gm-plantclosing-production-cars/. Accessed 12/8/2018. 